\title{
Postaerobic Exercise Blood Pressure Reduction in Very Old Persons With Hypertension.
}

Oliveira J, Mesquita-Bastos J, Argel de Melo C, Ribeiro F.

\section{Abstract \\ BACKGROUND AND PURPOSE:}

A single bout of aerobic exercise acutely decreases blood pressure, even in older adults with hypertension. Nonetheless, blood pressure responses to aerobic exercise in very old adults with hypertension have not yet been documented. Therefore, this study aimed to assess the effect of a single session of aerobic exercise on postexercise blood pressure in very old adults with hypertension.

\section{METHODS:}

Eighteen older adults with essential hypertension were randomized into exercise $(\mathrm{N}=9$, age: $83.4 \pm 3.2$ years old) or control $(\mathrm{N}=9$, age: $82.7 \pm 2.5$ years old) groups. The exercise group performed a session of aerobic exercise constituting 2 periods of 10 minutes of walking at an intensity of $40 \%$ to $60 \%$ of the heart rate reserve. The control group rested for the same period of time. Anthropometric variables and medication status were evaluated at baseline. Heart rate and systolic and diastolic blood pressures were measured at baseline, after exercise, and at 20 and 40 minutes postexercise.

\section{RESULTS:}

Systolic blood pressure showed a significant interaction for group $\times$ time $(\mathrm{F} 3,24=6.698 ; \mathrm{P}=$ $.002 ; \mathrm{np}=0.153)$. In the exercise group, the systolic blood pressure at $20(127.3 \pm 20.9 \mathrm{~mm} \mathrm{Hg})$ and 40 minutes $(123.7 \pm 21.0 \mathrm{~mm} \mathrm{Hg})$ postexercise was significantly lower in comparison with baseline $(135.6 \pm 20.6 \mathrm{~mm} \mathrm{Hg}$ ). Diastolic blood pressure did not change. Heart rate was significantly higher after the exercise session. In the control group, no significant differences were observed.

\section{CONCLUSIONS:}

A single session of aerobic exercise acutely reduces blood pressure in very old adults with hypertension and may be considered an important nonpharmacological strategy to control hypertension in this age group. 